\title{
IUCN
}

\section{Sport and Biodiversity}

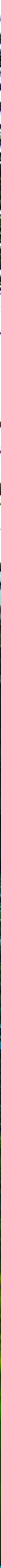

INTERNATIONAL UNION FOR CONSERVATION OF NATURE 


\section{About IUCN}

IUCN is a membership Union uniquely composed of both government and civil society organisations. It provides public, private and non-governmental organisations with the knowledge and tools that enable human progress, economic development and nature conservation to take place together.

Created in 1948, IUCN is now the world's largest and most diverse environmental network, harnessing the knowledge, resources and reach of more than 1,300 Member organisations and some 10,000 experts. It is a leading provider of conservation data, assessments and analysis. Its broad membership enables IUCN to fill the role of incubator and trusted repository of best practices, tools and international standards.

IUCN provides a neutral space in which diverse stakeholders including governments, NGOs, scientists, businesses, local communities, indigenous peoples organisations and others can work together to forge and implement solutions to environmental challenges and achieve sustainable development.

Working with many partners and supporters, IUCN implements a large and diverse portfolio of conservation projects worldwide. Combining the latest science with the traditional knowledge of local communities, these projects work to reverse habitat loss, restore ecosystems and improve people's well-being. 
Sport and Biodiversity 
The designation of geographical entities in this publication, and the presentation of the material, do not imply the expression of any opinion whatsoever on the part of IUCN concerning the legal status of any country, territory, or area, or of its authorities, or concerning the delimitation of its frontiers or boundaries.

The views expressed in this publication do not necessarily reflect those of IUCN.

This publication has been made possible in part by funding from the International Olympic Committee.

Published by:

IUCN, Gland, Switzerland

Copyright:

(c) 2018 IUCN, International Union for Conservation of Nature and Natural Resources

Reproduction of this publication for educational or other non-commercial purposes is authorised without prior written permission from the copyright holder, provided the source is fully acknowledged.

Reproduction of this publication for resale or other commercial purposes is prohibited without prior written permission of the copyright holder.

Citation: $\quad$ IUCN (2018). Sport and Biodiversity. Gland, Switzerland: IUCN. viii+24pp.

ISBN:

978-2-8317-1893-4

DOI:

https://doi.org/10.2305/IUCN.CH.2018.04.en

Cover photo:

Trail running in the forest (C) iStock

Layout by:

Imre Sebestyén jr / Unit Graphics

Available from:

IUCN (International Union for Conservation of Nature)

Business and Biodiversity Programme

Rue Mauverney 28

1196 Gland

Switzerland

Tel +41229990000

Fax +41229990002

biobiz@iucn.org

www.iucn.org/resources/publications 


\section{Table of Contents}

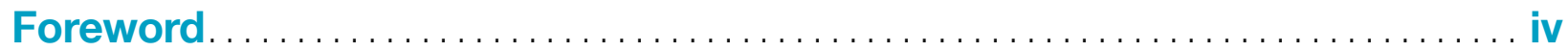

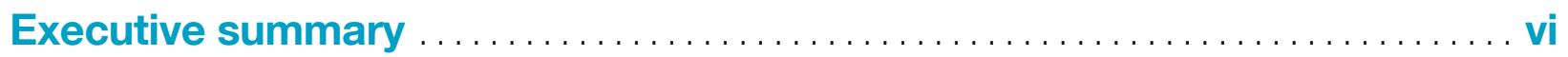

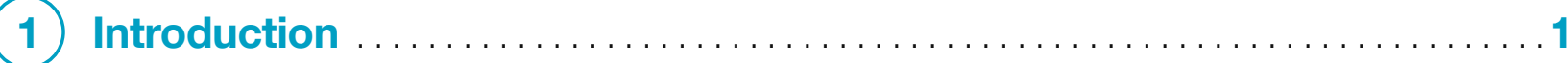

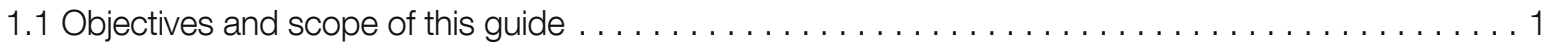

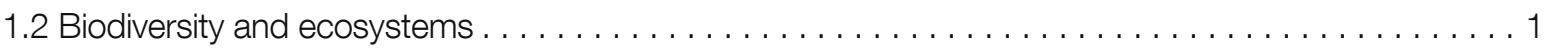

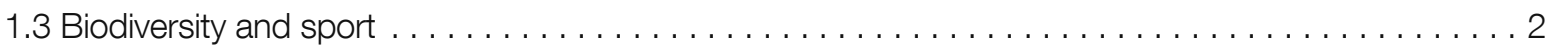

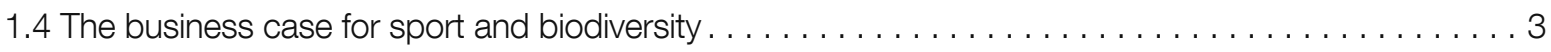

(2) Managing the impacts of sports venues and sporting events on biodiversity .5

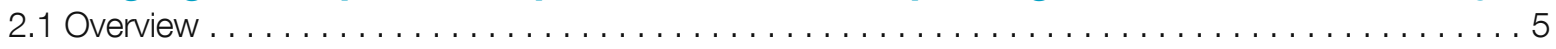

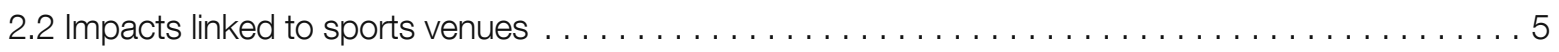

2.3 Impacts linked to the organisation of sporting events $\ldots \ldots \ldots \ldots \ldots \ldots \ldots \ldots \ldots \ldots \ldots \ldots \ldots \ldots \ldots \ldots \ldots$

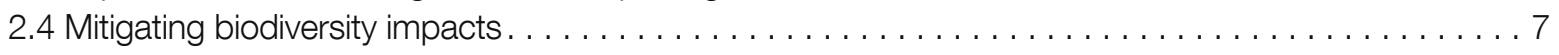

(3) Maximising opportunities for biodiversity conservation. . . . . . . . . 10

3.1 Enhance, restore, and reconnect natural habitats in urban environments $\ldots \ldots \ldots \ldots \ldots \ldots \ldots$

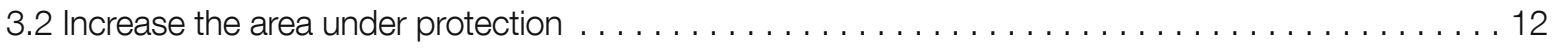

3.3 Generate funds for financing protected areas management $\ldots \ldots \ldots \ldots \ldots \ldots \ldots \ldots \ldots \ldots$

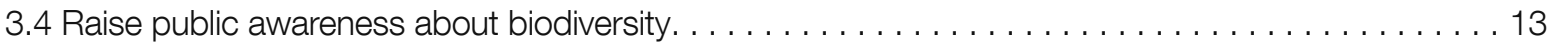

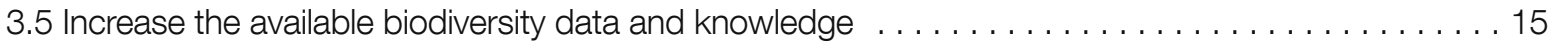

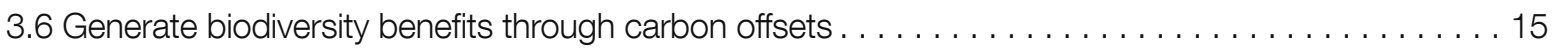

(4) An action checklist to mitigate risk and leverage opportunity ........ 17

5 Glossary and resources................................... 20

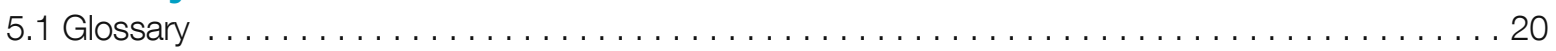

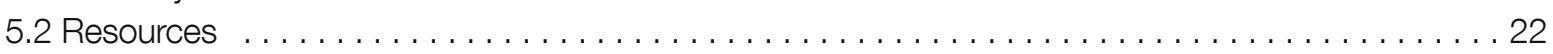




\section{Foreword}

With the world population expected to reach 9 billion by 2030 , our natural environment is facing unprecedented pressures due to human activity.

But let us be clear: we need nature. Today, we are in a race to safeguard the rich ecosystems that provide us with food, water and shelter. And there is growing evidence that suggests that just spending time in nature - including for outdoor sports activities - can significantly enhance our health and well-being.

The sport industry also needs nature. Whether it is skiing, canoeing, hiking or cycling, sports activities depend on a healthy environment.

At the same time, sport facilities such as football stadiums and ski resorts - and the sheer number of spectators at mega sport events - have a significant impact on the environment. The sport industry has a responsibility - as well as an interest - in ensuring that its operations are sustainable.

This IUCN guide, Sport and Biodiversity, highlights how sport federations, local organising committees, investors, athletes and fans can help reduce the industry's environmental footprint. From restoring degraded land to supporting protected areas, the industry can contribute to conservation and raise awareness among its spectators about the invaluable benefits that nature provides.
Furthermore, collective action by the industry can contribute to global efforts to achieve the goals set out in the United Nations' 2030 Agenda, which recognises sport as 'an important enabler of sustainable development'.

This guide is the first in a series of publications that will be produced under the IUCN-International Olympic Committee partnership. It provides an overview of the linkages between biodiversity and sports for developers of sports infrastructure and event organisers, outlining steps they can take to reduce the negative impacts on nature, from their venue planning and construction to the actual operations and the legacy they leave behind. The guide also explains why ignoring biodiversity impacts can pose a number of business risks to the industry.

IUCN is proud to team up with the International Olympic Committee. We look forward to strengthening the links between the sports and conservation communities to address one of our most important challenges of our time safeguarding our planet. This is a race we cannot afford to lose.

Inger Andersen, Director General, International Union for Conservation of Nature 


\section{Foreword}

Sport takes place in all kinds of environments, from marine and natural wetlands, to urban parklands, forests, mountains and even deserts. In all these situations sport has a strong connection with biodiversity. Indeed, any natural site, or greenspace used for sport will have some interaction with biodiversity, and with careful management these sport places can potentially be even more valuable as sanctuaries for many kinds of wild plants and animals.

Sport parks in urban areas can also support a wide range of biodiversity, and they play a vital role as neighbourhood greenspaces, offering community benefits beyond their sporting function. Sport buildings - stadia and sports halls - can be part of city greening initiatives, from green roofs and walls, to surrounding landscaping and drainage systems.

Some city centre sports facilities have gone to the extent of having their own organic food growing areas and beehives.

Looking beyond the physical footprint of sport places, the sport sector can have a considerable impact on biodiversity through the goods and materials it purchases and greenhouse gas emissions from day-to-day activities.

Therefore, whatever the specific context, we believe that everyone in the sporting community has an important duty of care - or stewardship towards the natural environment and for protecting biodiversity. It is part of our natural world and a vital part of what makes sport so special.
The IOC is therefore delighted to have formed a partnership with the International Union for the Conservation of Nature (IUCN), the world's premier organisation for biodiversity conservation. Our mutual goal is to work together to foster better understanding and protection of biodiversity through sport.

This guide produced by IUCN is an example of our partnership in action. It provides an excellent overview of the synergies between sport and biodiversity and is a valuable complement to our own Sustainability Strategy arising from Olympic Agenda 2020, the IOC's strategic roadmap.

We hope it will inform and inspire everyone in the sporting world to take a closer look at how their sport activities interact with the natural environment, and what they can do to foster biodiversity conservation.

Christophe de Kepper, Director General, International Olympic Committee 


\section{Executive summary}

Sport can have significant negative impacts on biodiversity, through the construction and use of sports venues and the staging of sporting events. This guide is designed to help decision makers understand these potential impacts, and to present options for mitigating them, as well as for maximising opportunities to use sport as a way to promote and enhance biodiversity conservation.

Biological diversity, or biodiversity in short, is defined by the Convention on Biological Diversity as the '.. variability among living organisms from all sources including, inter alia, terrestrial, marine, and other aquatic ecosystems and the ecological complexes of which they are a part; this includes diversity within species, between species, and of ecosystems'.

Biodiversity supports valuable ecosystem services that are essential for the survival and healthy functioning of human society and its economic activities. However, despite this, human activity is leading to an alarming, and increasing, rate of biodiversity loss across the world's ecosystems.
Sport can negatively impact biodiversity through land use to build permanent or temporary sports venues and facilities, as well as through the pollution, noise, waste, lighting, traffic, and resource demand resulting from the staging of sporting events attended by hundreds or thousands of spectators. At the same time, sport, through its global reach, can be an important catalyst for raising awareness about the need for biodiversity conservation, and promoting and supporting efforts to enhance biodiversity.

Understanding and managing the potential negative impacts and opportunities for conservation is vital for ensuring that sports venues and sporting events deliver successfully both from the financial and operational standpoint. Unmanaged or poorly managed biodiversity impacts can lead to financial, regulatory, operational, and reputational risks. On the other hand, timely and effective action to mitigate risks and enhance conservation can help venues and event planners and organisers increase their social license to operate, more easily attract future sporting events, establish long-term positive relationships with communities and the media, and attract sponsors.

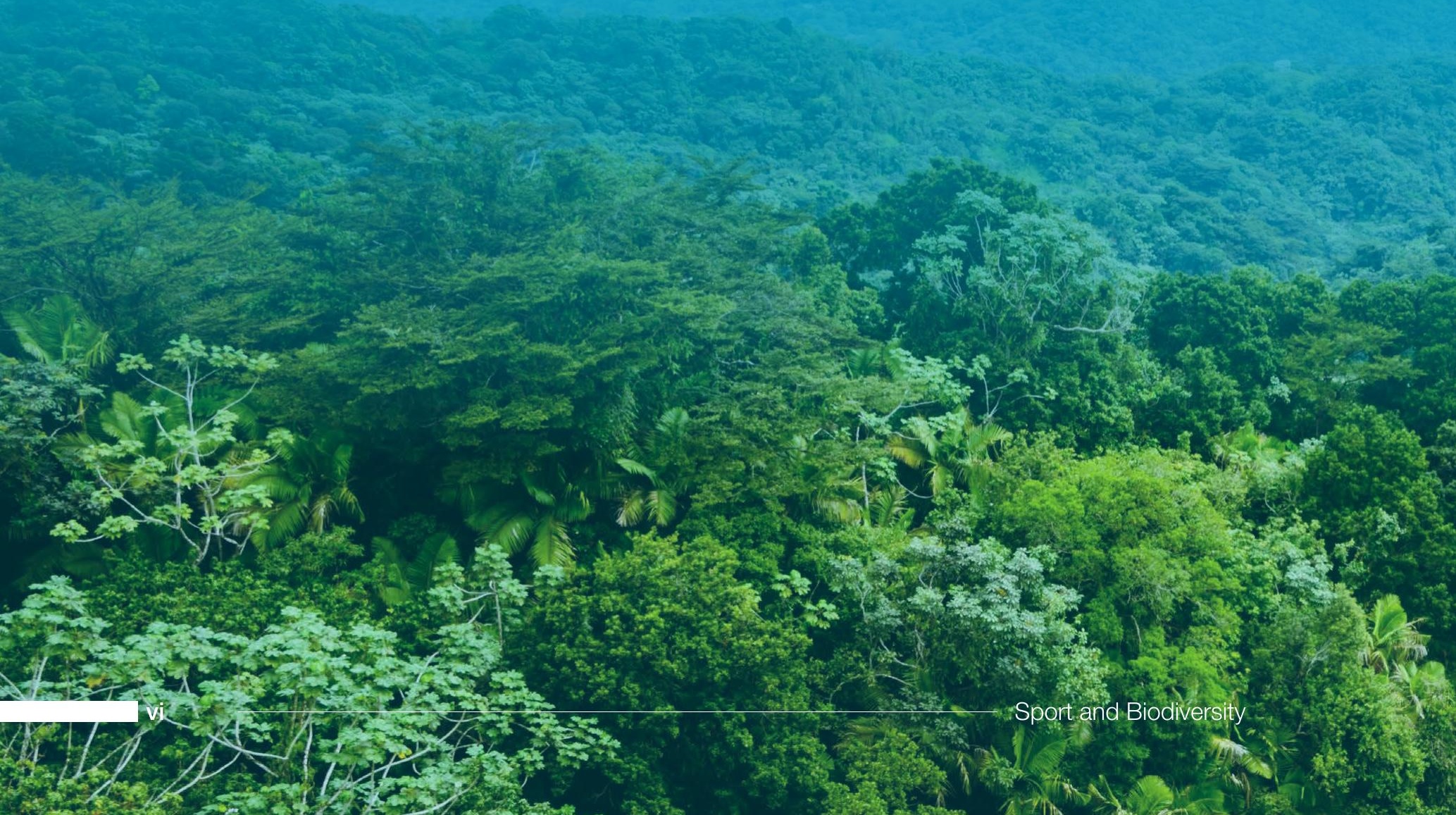




\section{Mitigating negative impacts on biodiversity}

The construction of new sports venues, the installation of temporary venues and associated facilities, and the use and refurbishment of existing venues can all impact on biodiversity. The type of risks and opportunities will vary, depending mainly on the location of the venue (i.e. whether it is sited in an urban area or in the natural environment, and the importance of that environment for biodiversity) and on its size. While the impacts may be broader, more severe, and more obvious in a natural, undeveloped area, where it is often necessary to construct access roads, power supply infrastructure, and water and sewer infrastructure (amongst others), there are also risks to developing in urban areas, where many species make their homes within the built environment.

The staging of sporting events in both urban and natural settings can impact biodiversity through the presence of large numbers of spectators, who increase noise, vibration, pollution, waste generation, and traffic. Other risks to biodiversity from sporting events include oil or fuel spills, sewage discharge, light pollution, increased use of chemicals and fertilisers, and increased demand for natural resources.

To address these potential impacts, developers should first comply with all legal and statutory requirements relating to biodiversity. Beyond compliance, the recommended way to manage biodiversity impacts effectively is through the mitigation hierarchy of avoidance, minimisation, restoration, and offsetting of residual impacts. Preventive mitigation measures (avoidance and minimisation) are always preferable to corrective measures (restoration and offsets).

\section{Maximising opportunities for biodiversity conservation}

Sporting events and their associated facilities can leverage opportunities to promote and support biodiversity conservation through a variety of activities and initiatives, including:

- enhancing natural habitats in urban environments by restoring degraded sites, connecting fragmented habitats, building 'green' rooftops and living walls, installing man-made habitats for wildlife, increasing the diversity of plant species, and incorporating plantings in their project design that provide additional habitat and benefits to local fauna and flora;

- increasing the area under protection through on-site or off-site protection of natural features;

generating funds and increasing awareness for protected area management by staging low-impact sporting events, such as running or

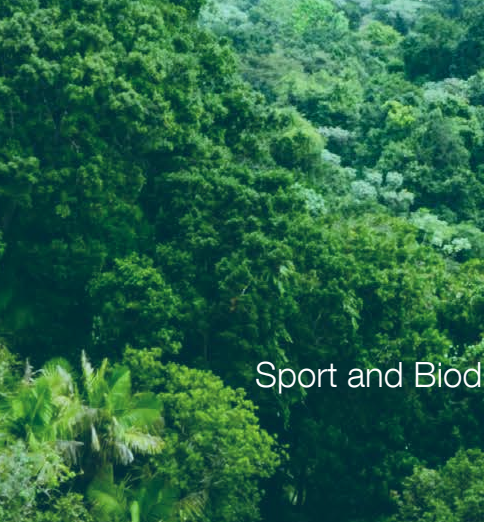

mountain biking, within or partially within protected areas;

- raising public awareness about biodiversity through the use of biodiversity elements as mascots or as part of an event's logo, and the creation of public exhibits and educational programs, as well as through sports commentators and individual, high-profile athletes;

- increasing available knowledge and data by sharing biodiversity inventories and baseline information that may be required as part of venue development with conservation organisations. and research institutions; and site

- generating biodiversity benefits through projects designed to offset the carbon footprint of a venue or event.

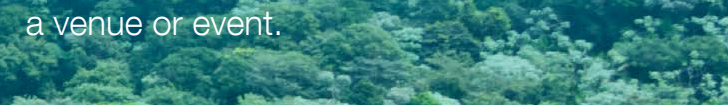
(a)

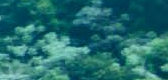
Hom
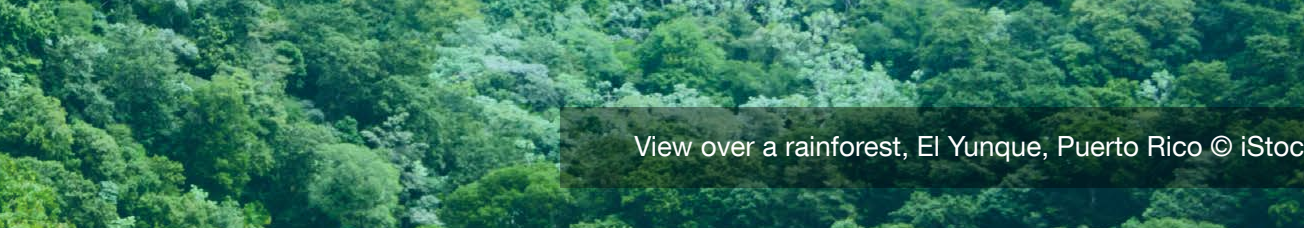

View over a rainforest, El Yunque, Puerto Rico ๑ iStock sects

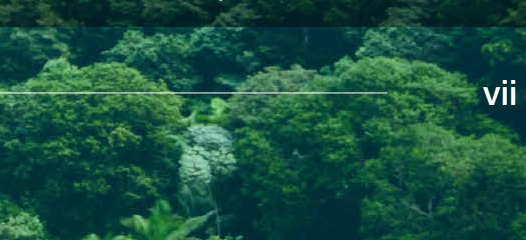




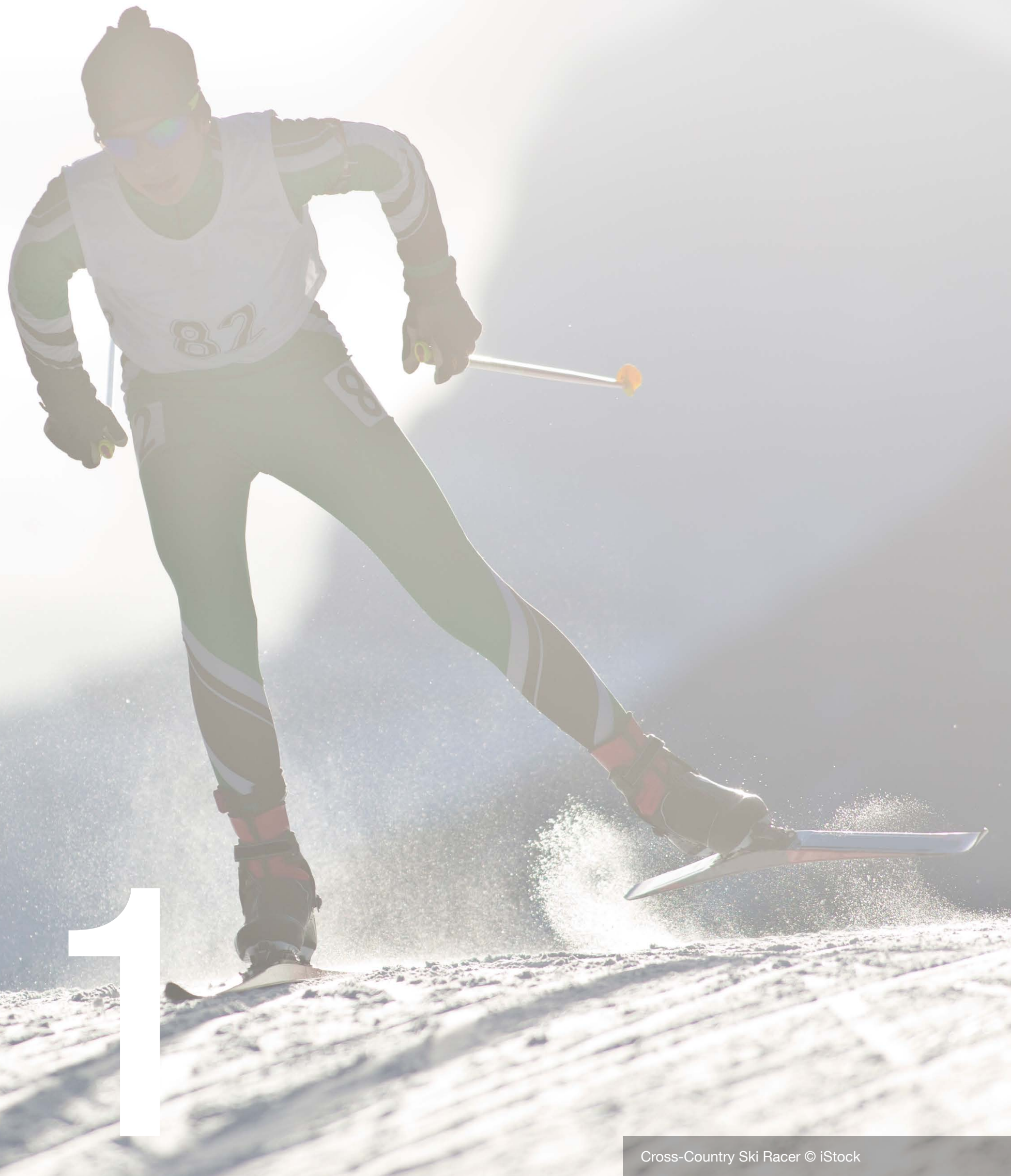




\section{Introduction}

\subsection{Objectives and scope of this guide}

The objectives of this guide are to:

- explain what biodiversity is and how it can be impacted by the construction of sports venues and the staging of sporting events;

- present ways of mitigating potential negative impacts on biodiversity from sport; and

- $\quad$ highlight the biodiversity opportunities available to the sports community.

The guide has been written for all sport-related decision makers, from city authorities, who are key players in the development of new venues and bidding for sporting events, to planners, architects, and engineers tasked with choosing the location and the design and construction or refurbishment of sports venues; from venue owners/operators to regional government officials; and from national and international sports federations to Local Organising Committees (LOCs) responsible for the planning and staging of events.

The topics presented in this guide are relevant to local and international events, small and mega-events, indoor and outdoor sports, summer and winter sports, temporary infrastructure, refurbishment of existing venues, and the construction of new, permanent venues.

\subsection{Biodiversity and ecosystems}

Biological diversity, or biodiversity in short, is defined by the Convention on Biological Diversity as the '.. variability among living organisms from all sources including, inter alia, terrestrial, marine and other aquatic ecosystems and the ecological complexes of which they are a part; this includes diversity within species, between species and of ecosystems'.
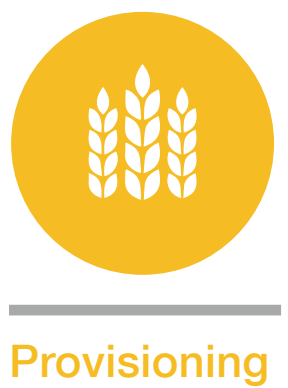

Services

are the material benefits people get from ecosystems for e.g. supply of food, water fibers, wood and fuels.

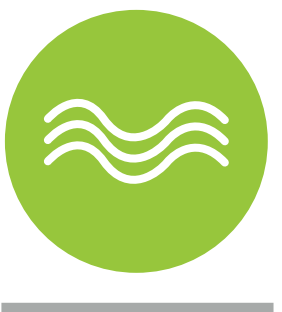

\section{Regulating}

\section{Services}

are the benefits obtained from the regulation of ecosystem processes o.g. the regulation presses e.g. the regulti of air quality and soil fertility control of floods or crop pollination
Biodiversity, and the life-sustaining ecological processes it enables and maintains, is the basis of innumerable ecosystem services that are essential for the survival of every individual and for the functioning of society and all its economic activities (see Figure 1).

Biodiversity loss is occurring at an alarming rate across the world's terrestrial, freshwater, and ma-
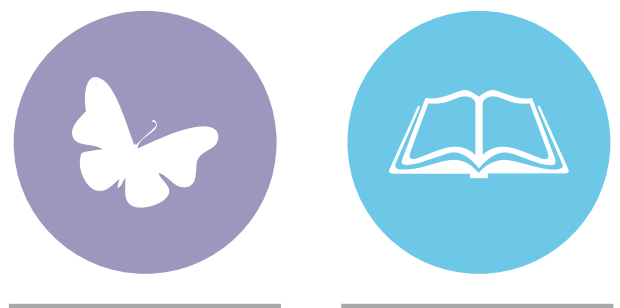

Supporting

\section{Services}

are necessary for the

production of all other

production of all other

e.g. by providing plants and

e.g. by providing plants and

animals with living spaces,

allowing for diversity of

species, and maintaining

genetic diversity.

Figure 1: Biodiversity and life-sustaining biological processes 
rine biomes. Much of Earth's biodiversity is under grave threat from the direct impacts of conversion of natural habitats, unsustainable extraction of natural resources, unchecked spread of invasive alien species, and pollution (see Figure 2). Climate change, directly and indirectly, is also profoundly impacting species and their habitats. Evidence is mounting that the loss of genes, species, and ecosystems jeopardises the delivery of critical services provided by biodiversity to human communities.

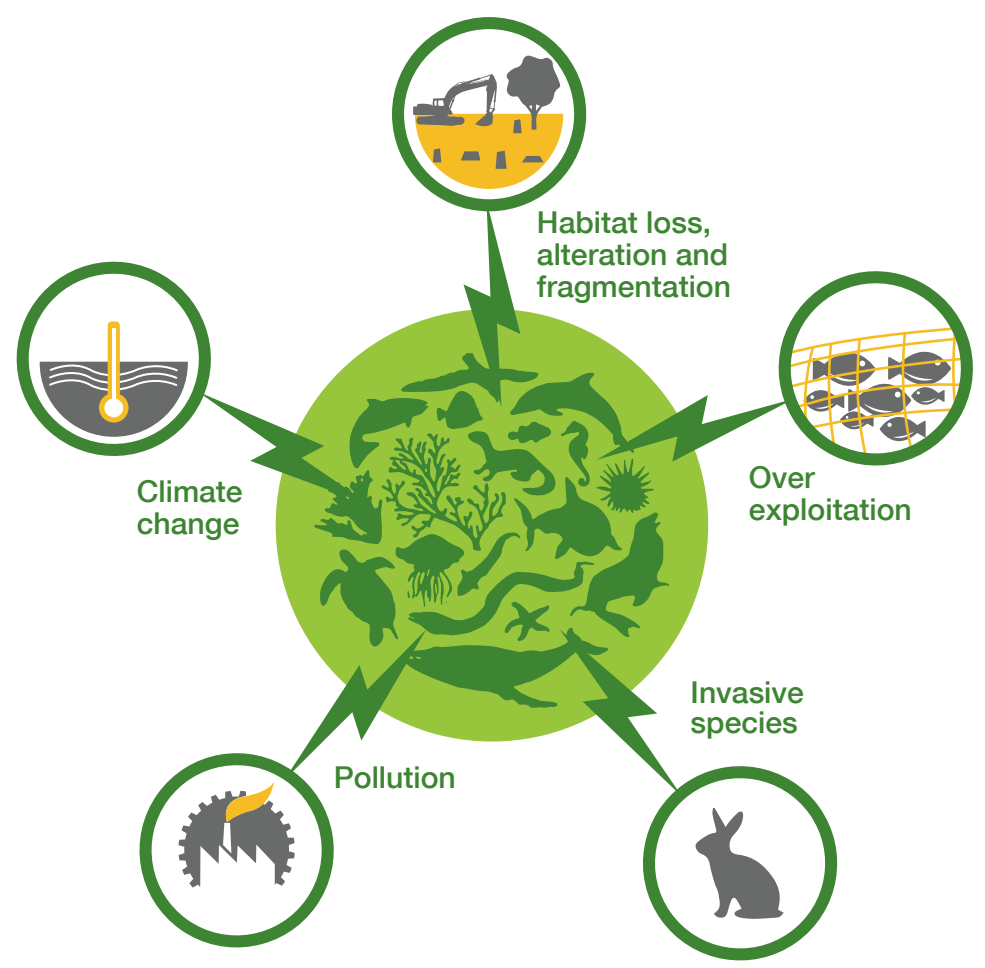

Figure 2: Direct pressures on biodiversity and ecosystems (Source: based on Millennium Ecosystem Assessment, 2005. Ecosystems and Human Well-being: Synthesis)

\subsection{Biodiversity and sport}

Sport can have negative impacts on biodiversity through the need for land area to construct permanent and/or temporary sports venues and support facilities. Further adverse impacts on biodiversity can arise from the demand for natural resources such as water, the generation of high quantities of solid waste and water pollution linked to the use of chemicals and the generation of municipal wastewater, and high levels of noise and light pollution triggered by the presence of hundreds to many thousands of athletes, spectators, and media, especially if in natural areas. However, sport, through its mass appeal and ever-increasing global reach, also has the potential to act as a positive force for biodiversity conservation.
Throughout the various phases of venue and event planning and delivery (conception, site selection, design and construction, staging, dismantling, and closure and venue redeployment), decisions can be made to conserve biodiversity, by both mitigating potential negative impacts and enhancing biodiversity resources. To do so successfully, it is critical to be aware of the interrelations between biodiversity and sport, and to ask the right questions (see Section 4) early enough, and continuously, so that identified measures can be more easily and effectively integrated in all the phases. 


\subsection{The business case for sport and biodiversity}

There are many reasons for taking timely action to effectively mitigate impacts on biodiversity linked to sport, as well as to maximise the opportunities for biodiversity conservation. Unmanaged or poorly managed biodiversity impacts can pose a number of risks to a sporting event, the most relevant being:

- Financial risks: A venue that may negatively impact biodiversity could encounter problems accessing project finance. Furthermore, construction delays related to conflicts with local communities and civil society organisations over poor management of biodiversity values can also lead to important financial costs for the developers and the organising committee.

- Regulatory risks: Biodiversity aspects play a central role in environmental impact assessment processes and environmental licensing by relevant authorities. In addition, failure to comply with local regulations could lead to large fines.

- Operational risks: Inadequately protected or managed environments can jeopardise the health of athletes and diminish the attractiveness of events and venues for the local community, spectators, and media.

- Reputational risks: Poorly managed impacts on biodiversity could result in criticism and campaigns by the media and civil society. This could impact an event through lower spectator attendance, difficulty in obtaining corporate sponsorships, and perception of a negative link between the biodiversity issue and the event/ sports federation.
On the other hand, taking timely and effective action to mitigate negative impacts and maximise conservation opportunities could lead to:

- accessing project finance and obtaining the necessary planning and environmental approvals easier and faster;

- a region, city, venue, or federation attracting future sporting events more easily, due to national and/or international recognition of best practice in the sector;

- establishing long-term positive engagements with civil society organisations, the local community, and the media that could benefit the overall sports sector and, specifically, the successful organisation of the event;

- obtaining a social license to operate by addressing civil society's concerns about the biodiversity impacts of the venue and sporting events;

- attracting sponsors that seek to promote sustainable products and/or want to associate their image with the environment and biodiversity;

- contributing to resilient cities and healthy lifestyles; and

- working to meet the Sustainable Development Goals, in particular Goal 14 'Life below water' and Goal 15 'Life on land', as well as the Convention on Biological Diversity's Aichi Biodiversity Targets. 


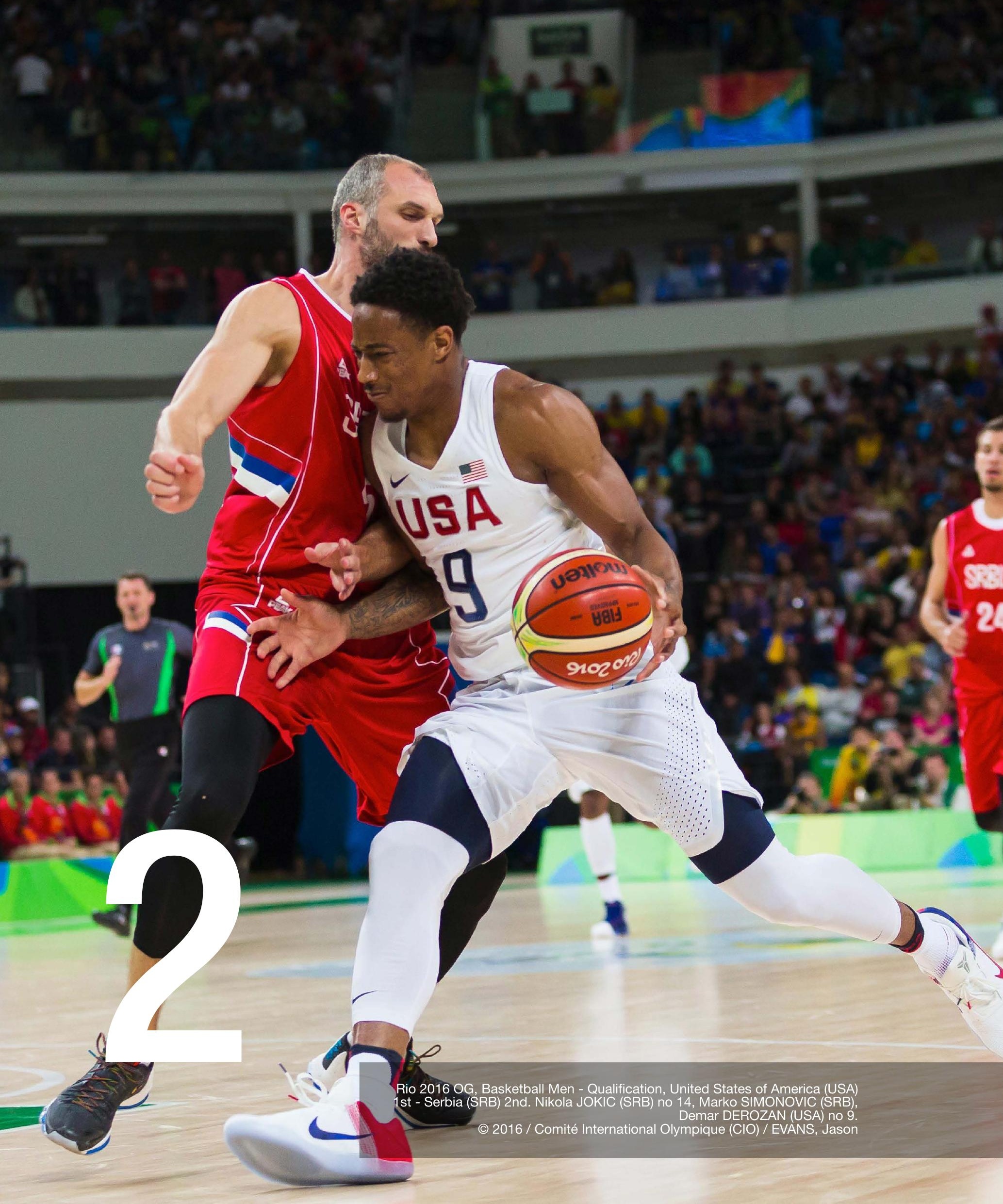




\section{Managing the impacts of sports venues and sporting events on biodiversity}

\subsection{Overview}

Biodiversity loss, which is the decline in the diversity of plants and animals (at genetic, species, and ecosystem levels), can be caused by:

- degradation, fragmentation, and loss of habitat;

- introduction of invasive species;

- pollution;

- climate change; and

- over-exploitation of natural resources.
The construction of new sports venues and supporting infrastructure such as access roads and powerlines; the installation of temporary venues and their associated facilities, including parking, spectator overpasses, temporary seating, public toilets, view-points, fencing, communication infrastructure, commercial outlets, etc.; and the staging of sporting events can all directly or indirectly contribute to these pressures.

\subsection{Impacts linked to sports venues}

The location and size of a venue will determine the type of risks, as well as the opportunities, that will be faced. Sports venues can be located in urban or natural environments, the key difference being that urban environments are generally considered, from a biodiversity point of view, as being largely 'modified habitats', while natural environments would generally qualify as either 'natural habitats' or 'critical habitats' (see Box 1).

Natural habitats are generally more sensitive than modified habitats to the changes associated with the construction of new venues, especially when a large land area and the construction of large and complex facilities are involved. Critical habitats, given their significance for biodiversity conservation, are likely to be most sensitive to these changes. On the other hand, sports venues in highly modified areas may have an opportunity to restore degraded areas as part of their development. Generally, the size of a new venue defines the level of impacts in a particular environment, while the use of existing venues can avoid land-use-related impacts associated with the construction of a new facility.

\section{Box 1. Modified, natural, critical habitats ... What's the difference?}

Modified habitats are 'Areas that may contain a large proportion of plant and/or animal species of non-native origin, and/or where human activity has substantially modified an area's primary ecological functions and species composition'. Natural habitats, on the other hand, are defined as 'Areas composed of viable assemblages of plant and/or animal species of largely native origin and/or where human activity has not essentially modified an area's primary ecological functions and species composition'. Critical habitats are a subset of either natural or modified habitats, and are defined as ... area[s] of the planet with high biodiversity conservation significance based on the existence of habitat of significant importance to critically endangered or endangered species, restricted range or endemic species, globally significant concentrations of migratory and/or congregatory species, highly threatened and/or unique ecosystems and key evolutionary processes'. 
When new venues - permanent or temporary - and their associated infrastructure are developed in natural or critical habitats, they can contribute to habitat degradation, fragmentation, and loss, especially if they have a large footprint. The magnitude of this impact will also greatly depend on the biodiversity values of the area; developing sports venues in or within close proximity to marine, coastal, and/ or terrestrial protected areas, Key Biodiversity Areas, World Heritage Sites, Ramsar sites, or Important Bird and Biodiversity Areas would come with high risks to biodiversity. Although a natural habitat may not have a special designation, it will most certainly have a wide variety of plant and animal species that may be affected. It is also important to recognise that, in certain situations, even if the direct footprint impact of the venue on biodiversity is minimal, it could make an already critical situation worse. New sports venues, including the range of infrastructure such as access roads, power lines, and pipelines needed to support them, may also fragment habitat and natural corridors in the landscape. These impacts add to the footprint impacts and could result in a cumulative negative impact that would make it impossible for a natural community, habitat, or a species to persist.
When sports venues are developed in modified environments, such as in urban settings, it might seem on the surface that there is no risk to biodiversity, since buildings and built features are not expected to harbour much wildlife. However, with their variety of construction, urban areas are important habitats for a wide range of species that use walls, bridges, rooftops, and other parts of built structures for roosting, nesting, breeding, and colonising. Bats, birds, lichens, mosses, wildflowers, and many mammals and invertebrates call urban buildings 'home'. Disruptions to these locations from the demolition of old buildings to make way for new infrastructure; the refurbishment of existing buildings; the installation of temporary infrastructure needed for event operations; increased lighting, vibrations, and dust; or other physical changes to their habitats can have a considerable impact on urban plant and animal species. This, combined with the general lack of acknowledgement and information about the biodiversity aspects of the urban environment, means that managing biodiversity in these areas is often not part of project planning. Therefore, impacts are often unknown and unintended.

\subsection{Impacts linked to the organisation of sporting events}

Sporting events held in urban venues or in natural landscapes can negatively impact biodiversity through large numbers of spectators, who increase noise, vibration, and lighting, produce large quantities of solid waste and wastewater, and generate traffic that can increase pollution and road kills of wildlife. Furthermore, outdoor venues in or near urban areas that are used for recreation and leisure activities are frequently highly managed environments.

When a sporting event is staged, there can be a significant increase in management activities, such as increased cutting of grass, brush, undergrowth, or borders. The removal of this vegetation (e.g. cut grass, fallen leaves, dead wood) can disrupt or destroy biodiversity habitats. The application of chemical fertilisers, pesticides, and mosquito control measures, can further affect, reduce, or limit the opportunities for species survival in these intensively managed environments.

The risks to biodiversity from both summer and winter sporting events conducted outdoors in natural environments come from many sources, including oil or fuel spills; solid waste generation; the use of cleaning products, pesticides or herbicides; discharge of sewage into the water or on land; the introduction of invasive species; noise, lighting and vibration; traffic and road kills; and the need, even temporarily, to erect fencing and communication infrastructure, and expand and/or construct new start and finish areas, viewing points, media points, medical stations, refuelling stations, commercial outlets to service the event, and water reserve ponds for snowmaking.

Spectators can also damage natural habitats through the sheer numbers of people trampling the grounds. Littering, walking on non-designated paths and into sensitive areas, and car and bike parking where not permitted can all have negative impacts on biodiversity, such as disturbing breeding, nesting, and feeding animals. These behaviours in fragile outdoor spaces can impact both biodiversity and habitats negatively and, in some cases, irreversibly. 


\subsection{Mitigating biodiversity impacts}

In most countries, environmental regulations govern the development of new sports venues or the expansion and modification of existing venues. This guide does not address this topic, except to state that sports organisers should comply with all legal requirements that relate to biodiversity.

Within and beyond legal compliance, the recommended way of effectively managing biodiversity impacts is through what is known as the 'mitigation hierarchy' of avoidance, minimisation, restoration, and offsets (see Figure 3 and Box 2). The mitigation hierarchy comprises a sequence of actions to address negative impacts on biodiversity. According to the mitigation hierarchy, wherever possible, impacts should be avoided. Where avoidance is not possible, impacts are to be minimised. These impacts should then be mitigated through restoration actions, and, where significant residual impacts still remain, biodiversity offsets should be implemented. Mitigation measures that avoid and then minimise impacts are prioritised over measures to correct or

\section{Box 2: The IUCN policy on biodiversity offsets}

The 2016 IUCN Policy on Biodiversity Offsets highlights a number of fundamental principles that should be taken into consideration for effective implementation of the mitigation hierarchy. These include:

1. Apply the hierarchy as early as possible in the project life cycle, to inform potential development decisions.

2. Explicitly consider the project within a broader landscape or seascape context.

3. Identify and respect nationally and internationally recognised 'no-go' areas.

4. Examine lower-impact alternatives in the project design, including not proceeding with the project

at all, recognising that not all impacts can be offset to achieve no net loss.

5. Give priority to avoiding any damage to biodiversity.

6. Take full account of direct, indirect, and cumulative impacts, both geographically and over time.

7. Clearly distinguish impact avoidance, minimisation, and on-site restoration measures from offsets.

8. Design offsets to achieve at least no net loss and preferably a net gain of biodiversity.

9. Ensure any biodiversity offsets used as part of the mitigation hierarchy secure additional conservation outcomes that would not have happened otherwise.

10. Use approaches that are science-based, transparent, and participatory, and that address the effects of the project and mitigation actions on livelihoods.

11. Follow a rights-based approach, as defined by IUCN resolution WCC

-2012-Res-099.

12. Identify and put in place the legal, institutional, and financial measures needed to ensure longterm governance of all mitigation actions (including any biodiversity offsets).

13. Apply a rigorous monitoring, evaluation, and enforcement system that includes independent verification of all mitigation actions.

14. Apply the precautionary principle throughout all stages of the mitigation hierarchy.

15. Apply the ecosystem approach in all stages of the mitigation hierarchy.

IUCN's Policy also recognises that there are limits to biodiversity offsetting, and that 'In certain circumstances residual impacts on biodiversity (after completing the avoidance, minimisation and rehabilitation steps of the mitigation hierarchy) cannot be offset. Additionally, there are some components of biodiversity for which impacts could theoretically be offset, but with a high risk of failure. Under these circumstances, biodiversity offsets are not appropriate, and this means that the project as designed should not proceed.'

Source: IUCN website 


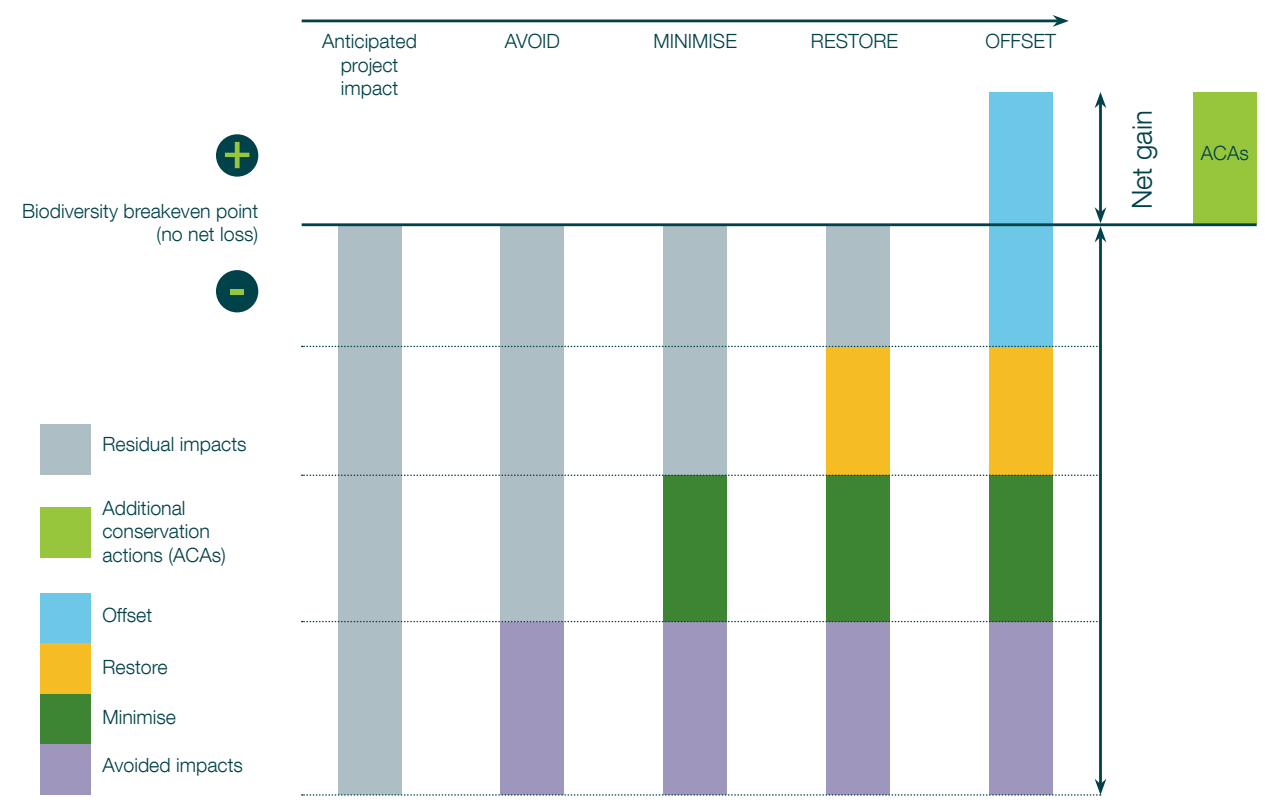

Figure 3: The mitigation hierarchy

(Source: adapted from the Business and Biodiversity Offsets Programme (BBOP))

remedy impacts, given the risks associated with restoration and offsets. For this reason, the utmost care should be taken in choosing a suitable location for a new sports venue and/or sporting event. Considering modified or degraded sites offers considerable benefits: the risks of negative biodiversity impacts are small and opportunities to benefit biodiversity conservation are greatest. The objective of all mitigation measures can either be set to achieve 'no net loss' or, even better, a 'net gain' of biodiversity.
Finally, it is important to involve an ecologist in the planning team for new sports venues and sporting events at an early stage, to help identify biodiversity risks and potentially significant impacts that would need to be mitigated. Failure to do so could result in delays and eventually additional costs. 



\section{Maximising opportunities for biodiversity conservation}

Sporting events and their associated facilities, including access roads, parking areas, etc., can catalyse biodiversity conservation at a local and global level. Identifying these opportunities can help strengthen the relationship between venue developers and event organisers, and local communities. Although a definitive list of opportunities does not exist, this section discusses some available options.

\subsection{Enhance, restore, and reconnect natural habitats in urban environments}

Any sporting event can trigger urban enhancement or renewal by restoring degraded sites, connecting natural sites and habitats that may have become fragmented over time, building 'green' rooftops and living walls, and installing man-made habitats suitable for use by animals such as birds and bats.

The construction of new permanent venues can offer an opportunity to bring back to use an existing degraded area, such as former landfill sites or abandoned industrial areas, instead of developing a 'green-field' area (see Box 3). The use of degraded land as a site for multiple new venues was a central part of the strategies for the Sydney 2000 Olympic Games, the London 2012 Olympic Games, and the Paris 2024 Olympic Games candidature. Through such a transformation process, organisers can help reverse pre-existing trends that have been damaging to urban biodiversity and habitats. Sporting events may also offer an opportunity to develop urban ecological corridors; these open spaces have the potential to provide multiple use benefits to urban dwellers.

There are many other options for improving the habitat in urban spaces, for example incorporating plantings that attract pollinators and nectar-feeding insects, and adding shelters for birds, bats, and invertebrates (see Box 4). Trees can be planted along roads to encourage biodiversity in the built environment. Species-rich lawns, ornamental trees, and shrubberies can be established using native species, together with plants that provide benefits to other local fauna and flora. Wetlands can be re-established in areas

\section{Box 3. Golf events restore industrial sites and native species}

It took vision, in Rio de Janeiro, to look at a degraded old quarry site, overrun with 80 percent non-indigenous vegetation cover, and see the potential for redesign as a natural golf course with biodiversity protection and enhancement at the core of its design. But this is just what happened at the Rio 2016 Olympic Games, where an unused quarry site was transformed into a 'naturalised' golf course. The transformation led to a 167-percent increase in vegetation cover and a net increase in biodiversity, from 118 species found on site before the project to 263 species afterwards. The site was also quickly recolonized by rare and protected species, including burrowing owls, caiman, capybara, lapwings, sandpipers, and egrets. To achieve this state, more than 15,000 native plants were transplanted to the area, and an on-site plant nursery was developed to propagate more than 475,000 plants from native seeds to stock the site.

Source: Julie Duffus (Interview, July 2017), Organising Committee of the Olympic and Paralympic Games Rio 2016 


\section{Box 4. Sport leading the Solent oyster revival}

When the Land Rover BAR sailing team began to build their new home on the waterfront in Portsmouth, the team identified a threat to the natural ecosystem on their doorstep. The Solent, the strait that separates mainland England from the Isle of Wight, had once supported an oyster trade worth millions of pounds. However, in the last few years, a rapid decline in the native oyster population had led to the subsequent collapse of the oyster fishery in the area.

With an opportunity to make a real impact on the ecosystem on their doorstep, the team were excited to help make a difference. The concept was simple: Working with their partners, they would nurture protected cages of adult oysters at the team base, replicated on pontoons to reproduce and 'reseed' the wider fishery.

The oyster cages are now installed, and oysters are successfully establishing themselves back in the harbour. Dr Joanne Preston of the Institute of Marine Sciences, Portsmouth University, commented: 'It's fantastic to see stage one complete. The oysters are in, so we can now start collecting the data to gain a better understanding into what is happening to the oysters and the ecosystem around them'.

Source: LandRover BAR

where they might previously have been drained, with drainage features and planting of reed beds and other locally appropriate native wetland plants.

Increasing the diversity of plant species, grasses, and trees can increase the richness of a habitat. For example, low-growing wildflowers can be introduced into a green field to increase the species mix; a grassland habitat can be created around the margins of a football pitch, hockey field, or tennis courts; and buildings can be partially or completely covered with vegetation to create living 'green' roofs and/or walls. Instead of a water fountain, ponds can be built; reed beds can be introduced in a water body to clean the water and attract biodiversity; or log walls can be used instead of cement walls and fences, to benefit insects and other invertebrates. All these are options that can serve the organisers' purposes for their events while at the same time improving urban environments and delivering biodiversity, as well as aesthetic, benefits.

There are many benefits of working with local conservation organisations, which can provide valuable contributions of knowledge on local biodiversity, propose suggestions and mitigation recommendations, and take the lead in implementing conservation projects (see Box 5). Ideally, these organisations should be contacted early in the planning stage, so that their input can help shape the design of sports venues, rather than later when damage may already have been done.

\section{Box 5: Reusing sports equipment for biodiversity}

Since 2001, the Wildlife Trusts and The Championships, Wimbledon have worked together to prevent it becoming 'game, set, and match' for Britain's smallest mammal, the harvest mouse (Micromys minutus). Some 36,000 tennis balls used at the world-famous tournament are recycled every year as homes for harvest mice, to help protect the endangered species from their many predators and the loss of their habitat from intensive farming.

With a small hole cut into the side, the tennis balls make excellent, waterproof homes. They are attached to poles about a metre off the ground, where the mice can make nests away from birds of prey and ground predators.

Now, besides Wimbledon, many lawn tennis clubs around the United Kingdom regularly donate their used tennis balls to local wildlife organisations to help them in their conservation efforts.

Source: Julie Duffus (Interview, July 2017), London Organising Committee for the Olympic and Paralympic Games (LOCOG) 


\subsection{Increase the area under protection}

Sport and sporting events can result in an increase of protected areas, either by promoting the extension of existing protected areas or by leading to the establishment of new protected areas. This increase may come as a result of the mitigation hierarchy, if a biodiversity offset is established, or through on-site protection. The protection and management of an area as a biodiversity offset present opportunities to ensure a long-term connection between the event and the newly created protected area, and associated positive publicity for the developer or sporting body. Contributions to the funding of ongoing management could be generated by using a percentage of the entrance fees for the venue, or through commercial sponsorship agreements.

Whereas a biodiversity offset may be considered a one-off action, there can be opportunities to ensure a long-term connection between the event and the newly created protected area, through funding as a percentage of the entrance fees or through commercial sponsorship agreements.

On-site opportunities to increase protected areas may arise when important habitats are identified during the planning process and then formally protected within the scope of the event development. For example, the creation of the Athens 2004 Olympic Rowing Centre provided the city with an opportunity to re-establish a wetland area that had become severely degraded (see Box 6). The Local Organising Committee successfully worked with the Ministry of Public Works to have a small airport removed, restore the wetland and the adjacent forest areas, and design and develop the venue as a natural lake, rather than an artificial one.

\section{Box 6. Re-instating wetlands: from degraded site to rowing centre to national park}

A degraded wetland near the coast on the outskirts of Athens was chosen as the ideal spot to create a rowing centre for the 2004 Olympic Games. However, a multitude of anthropogenic pressures had caused considerable environmental degradation, to the point where there was a high risk of extinction for endemic freshwater fish and rare plant species in the area.

During the planning phase, the habitat and the project were treated as a single system, which was studied from environmental-ecological, area planning, and social-financial points of view. The aim was to optimise the design and operations of the project in relation to the habitat, while at the same time determining measures and interventions for upgrading ecological functions and protecting the habitat.

The final layout of the rowing centre took into account all these parameters, and also met athletic requirements, as determined by international specifications. The sensitive balance of groundwater, two newly constructed semi-natural lakes, a wetland, and the maintenance of the sand dune pine tree forest featured prominently in the design. The whole area, including the rowing centre, has since been designated as the Shineas National Park, to promote environmental protection as well as recreation and sports activities. This case is a clear example of how biodiversity enhancement can coexist with sport and provide lasting positive benefits for all.

Source: George Kazantzopoulos (interview, July 2017), Athens Organising Committee for the Games (ATHOC) 2004 


\subsection{Generate funds for financing protected areas management}

Low-impact sporting events in the natural landscape, such as running and mountain biking, offer real opportunities for marketing and generating funding for conservation through the visibility and exposure created by the event.

With their natural beauty, clean water, and clean air, protected areas offer attractive environments in which to conduct low-impact sporting events. Depending on the location, the type of habitat, the size of the event, and existing infrastructure or the possibility of setting up low-impact temporary infra- structure, sport and biodiversity may be compatible, and the event could support the primary purpose of the protected area, to ensure biodiversity conservation.

Because the event should comply with the applicable protection legislation and the zoning of the particular protected area, the events concerned will almost invariably be transient in nature, with no permanent sports venues or other dedicated sports infrastructure developed inside the protected areas.

\subsection{Raise public awareness about biodiversity}

Sporting events can provide a platform for raising local awareness about the importance of biodiversity and biodiversity conservation (see Box 7 and 8). They can also raise global awareness when the event welcomes spectators from around the world.
Through the multitude of media platforms now available, sporting events are powerful catalysts of public awareness and offer the possibility of raising the profile of biodiversity-related issues to a wide audience.

\section{Box 7. Cycling sensitively through beauty spots}

Box Hill is a Special Area of Conservation (SAC) and Site of Special Scientific Interest (SSSI) in the south of England. The area supports several nationally endangered species of plants and animals, among them two iconic species, the Adonis blue butterfly and the dormouse, as well as their food sources.

This area was part of the route for the London Surrey Cycle Classic and the cycling road races of the London 2012 Olympic Games. During planning, it was identified that spectators along the cycle route would be one of the major sources of potential impacts to the site.

Ecological surveys conducted with partners helped identify species sensitivity, created new knowledge about the species and their food plants, and provided information for spectator management planning, as well as for outdoor learning and environmental arts activities to raise awareness among spectators. These activities included film making, projects to create boxes for dormouse hibernation, and other initiatives to help spectators understand any restrictions on viewing the race and engage them in the natural qualities of the sporting event venue.

Source: Julie Duffus (Interview, July 2017), London Organising Committee for the Olympic and Paralympic Games (LOCOG) 


\section{Box 8: Swimming for conservation}

Two invasive species of lionfish (Pterois volitans and Pterois miles) are posing a growing threat to Atlantic and Caribbean reefs. The fish, which are native to the Indo-Pacific, are thought to have first been introduced along the south-eastern coast of Florida in the 1980s. Since then, the fish have spread rapidly north and south and are now found as far north as the Carolinas and throughout the Caribbean. They are now beginning to invade the Gulf of Mexico and the northern coast of South America. Wherever they spread, lionfish pose a serious threat to indigenous reef fish and coral reef ecosystems.

With no natural predators around the Bahamas, populations of lionfish have exploded and, in some areas, have decimated the reef ecosystem, leading to the collapse of fishing industries and significantly damaging the tourism industry.

In an attempt to control these invasive species, local communities on the Bahamian island of Eleuthera are using sport to help educate and raise awareness. An annual swimming event in which participants compete to catch as many lionfish as possible brings together sport and conservation in an effort to not only reduce the numbers of lionfish on the reefs, but also to educate people on the importance of preserving the reefs for future generations.

The event then goes a step further by holding a cookery class for all athletes and spectators, so that local community members can learn how to prepare and eat the fish, in the hopes that local fishermen will start fishing for the destructive invasive lionfish.

Source. Cape Eleuthera Institute (web)

It is important that the biodiversity messaging is relevant to the particular sport, sporting event, or spectator constituency. It should be about biodiversity and the related threats, and linkages with other sustainability issues such as heathy living, with the aim of generating support and/or changing behaviour and associated impacts. This is where partnerships with local conservation organisations and action groups can be beneficial.

The use of biodiversity elements represented as mascots, included on event tickets or staff uniforms, or as part of the event's logo, can have a powerful impact when associated with the right messaging. It is important to note, however, that the elements selected should be associated with the actual site of the event, or the local area, so that a real and logical communications narrative can be developed. The mascot needs a relevant and simple conservation message to be effective. Mascots appeal most when they evoke empathy by giving their characters human-like physical and behavioural features; empathy is essential to promote concern for animals and species. Beyond being seen as representative of a team and bringing luck, a mascot should help teach more about the species and its natural habitat and advocate for its survival and the protection of its habitat. Some examples include:

- All 18 of Florida Atlantic University's sports teams are known as the Owls, and the bird, which is traditionally associated with wisdom and determination, serves as the university's mascot. Since 1971, the school's campus in Boca Raton, Florida, has been the site of a designated Burrowing Owl sanctuary. This particular bird is listed as a 'Species of Concern' in Florida.

- Karak was the mascot for the 2006 Commonwealth Games. He was modelled on a redtailed black cockatoo, a threatened species in the host country, Australia.

- Fuleco the Armadillo was the official mascot of the 2014 FIFA World Cup in Brazil. Fuleco is a Brazilian three-banded armadillo, a species of armadillo that is native to Brazil and categorised as a Vulnerable Species in the IUCN Red List of Threatened Species ${ }^{\mathrm{TM}}$. The name is a combination of Futebol ('football') and Ecologia ('ecology'). 
From information panels and dedicated signs, to smart phone apps that share videos and photographs of biodiversity on land or on water, communications efforts can build longer-term appreciation in spectators of the value of biodiversity and how to help improve it. In addition, the same biodiversity information can be used to create curricula for local schools to teach students about the importance of biodiversity conservation in their local environment, or, it could be used to create a museum exhibit about biodiversity in the sports venue.

Sports commentators can also play a crucial role. They can enrich their event's presentations with details regarding the local biodiversity and any measures implemented by the event organisers. In addition, volunteers, sports officials, and event staff should also be briefed, so that they are able to explain any viewing restrictions, out-of-bounds areas, etc., to spectators and the reasons why. This can make all the difference between biodiversity protection measures being respected or not.

In raising public awareness on the importance of biodiversity conservation, athletes can be very effective biodiversity ambassadors through their direct connection with their fan base. Sports stars can positively influence attitudes and behaviours where they have a local link. For example, former basketball star Yao Ming, who is originally from Shanghai, uses his position as a role model to reverse centuries-old Chinese traditions that have resulted in dwindling rhinoceros and elephant populations. World-renowned soccer star Cristiano Ronaldo is an Ambassador of the Mangrove Care in Indonesia, through a forum that aims to raise awareness about the importance of conserving biodiversity and mangrove ecosystems in Bali.

\subsection{Increase the available biodiversity data and knowledge}

When natural sites are selected for sporting events, it is rare to know in advance exactly what animal and plant species exist in and around the area, and specifically where they are located. The biodiversity inventories and baselines often required as part of the venue planning and development authorisation process are therefore sources of new knowledge on an area for biodiversity conservation organisations that often do not have the means to collect such a wealth of data (i.e. universities, research centres, non-governmental organisations). Venue developers and local organising committees have a great opportunity to support future conservation by making these data publicly available.

\subsection{Generate biodiversity benefits through carbon offsets}

As for any human activity, sporting events, even the best designed and well-managed, should strive to offset the greenhouse gas emissions generated through the activities of the planning and staging phases. In selecting a carbon offset project, sports organisers could prioritise projects that would also generate biodiversity co-benefits.

Generally, land-management projects aim to deliver net positive benefits for climate change mitigation, for local communities, and for biodiversity. For example, forest-based carbon offset projects offer good opportunities to achieve carbon neutrality by addressing land degradation, a leading cause of global climate change, and also provide a suite of co-benefits, such as supporting local communities by ensuring the continued delivery of important ecosystem services that intact forests provide. Forest carbon projects also provide direct employment for community members and generate income and support for social and economic development initiatives. 


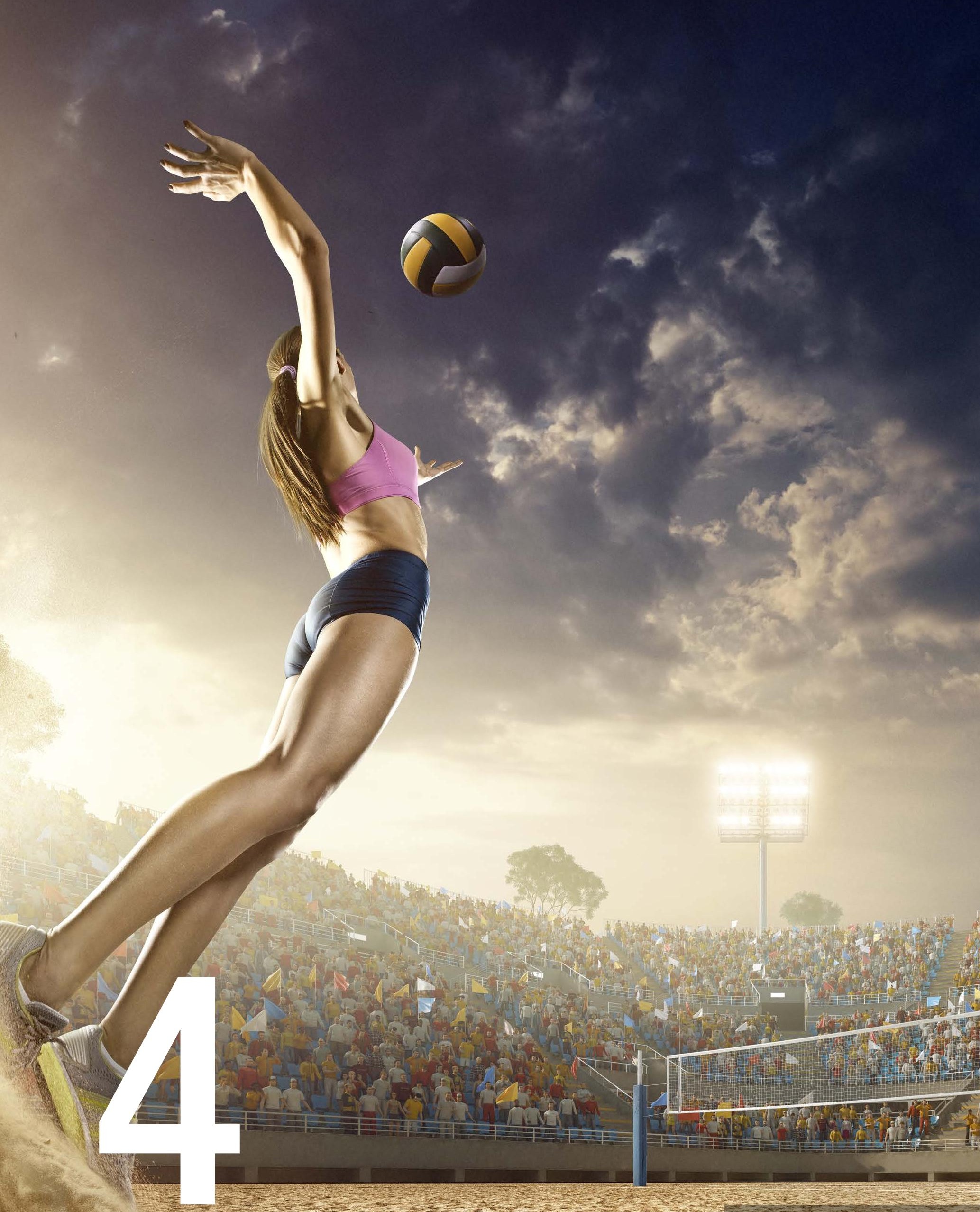

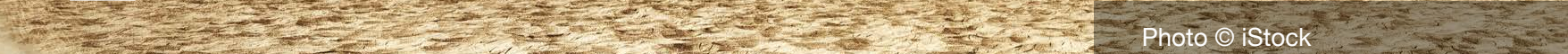

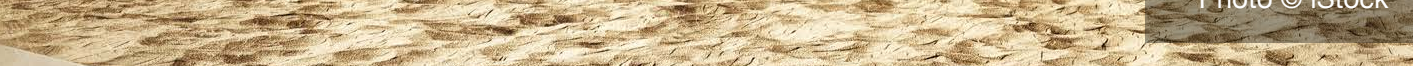




\section{An action checklist to mitigate risk and leverage opportunity}

The following table presents a range of action areas and associated guiding questions to help developers, organisers, and sponsors of sports venues and sporting events identify and address potential negative impacts on biodiversity from their activities, as well as opportunities for enhancing biodiversity conservation.

\begin{tabular}{|c|c|}
\hline Action area & Suggested questions to ask \\
\hline $\begin{array}{l}\text { 1. Determine if the } \\
\text { venue(s) and the } \\
\text { event(s) could have an } \\
\text { impact on biodiversity }\end{array}$ & $\begin{array}{l}\text { - Is the event going to use existing venues or will new venues be } \\
\text { built? } \\
\text { - Has an ecologist (or biodiversity specialist) been appointed as part } \\
\text { of the planning and design team? } \\
\text { - In relation to new venues, is there a detailed map of the } \\
\text { distribution of the local biodiversity values, such as protected } \\
\text { areas, key biodiversity areas, or habitats of threatened species or } \\
\text { ecosystems? } \\
\text { - Are the venues located or being built in World Heritage Sites or } \\
\text { protected areas? } \\
\text { - Is the area to be affected likely to have any 'critical habitat' (see } \\
\text { Box 2)? } \\
\text { - Have the costs of these impacts on the community been } \\
\text { assessed? } \\
\text { - Have the costs of mitigating the impacts on biodiversity been } \\
\text { assessed? } \\
\text { Have the benefits of mitigating the impacts on important } \\
\text { ecosystem services provided by the affected biodiversity been } \\
\text { assessed? }\end{array}$ \\
\hline $\begin{array}{l}\text { 2. Connect with } \\
\text { stakeholders }\end{array}$ & $\begin{array}{l}\text { - } \quad \text { Are there known conservation challenges in the area? } \\
\text { - Have the local conservation organisations, and international where } \\
\text { relevant, been contacted? } \\
\text { - Have relevant research institutions been contacted? }\end{array}$ \\
\hline $\begin{array}{l}\text { 3. Understand the } \\
\text { biodiversity impacts } \\
\text { of the venue and } \\
\text { sporting event }\end{array}$ & $\begin{array}{l}\text { - Has a detailed baseline survey of the biodiversity in the area been } \\
\text { conducted, to identify important biodiversity? } \\
\text { - Have pre-existing threats to biodiversity, which may be made } \\
\text { worse by the venue or event, been identified? } \\
\text { - Has an environmental impact assessment been planned or } \\
\text { conducted for new venues and events, to identify potentially } \\
\text { significant negative impacts and ways to mitigate them? }\end{array}$ \\
\hline
\end{tabular}




\begin{tabular}{|c|c|c|}
\hline & $\begin{array}{l}\text { Mitigate biodiversity } \\
\text { impacts }\end{array}$ & $\begin{array}{l}\text { - Have the impacts related to the venue and events been analysed } \\
\text { - } \quad \text { in terms of the potential for avoidance and minimisation? } \\
\text { - Where critical habitats in particular, or natural habitats, could be } \\
\text { negatively affected, have all feasible alternative sites for the venue } \\
\text { or event been investigated which would avoid these impacts? } \\
\text { - Have ways to avoid and minimise the impacts related to the venue } \\
\text { and events been addressed and included in implementation } \\
\text { plans? } \\
\text { - Has restoration of impacted habitat been assessed for its } \\
\text { feasibility and included in implementation plans? } \\
\text { - Have biodiversity offsets for impacts that remain after avoidance, } \\
\text { minimisation, and restoration efforts have been exhausted, } \\
\text { identified, and included in implementation plans? } \\
\text { Has the need for joint conservation action been addressed } \\
\text { through the establishment of partnerships with conservation } \\
\text { organisations and research institutions? }\end{array}$ \\
\hline & $\begin{array}{l}\text { Capture biodiversity } \\
\text { opportunities }\end{array}$ & $\begin{array}{l}\text { - Have opportunities to enhance and/or restore local degraded } \\
\text { habitats, and/or reconnect fragmented habitats, been used? } \\
\text { - Have opportunities to extend or expand protected areas been } \\
\text { considered? } \\
\text { - Have the data collected during the biodiversity assessment been } \\
\text { shared with relevant conservation and research institutions? } \\
\text { thave biodiversity awareness and information programmes } \\
\text { targeting the public been included in the staging of sporting } \\
\text { events? } \\
\text { - Have fundraising options for the management of protected areas } \\
\text { and local conservation initiatives been identified and planned? }\end{array}$ \\
\hline
\end{tabular}




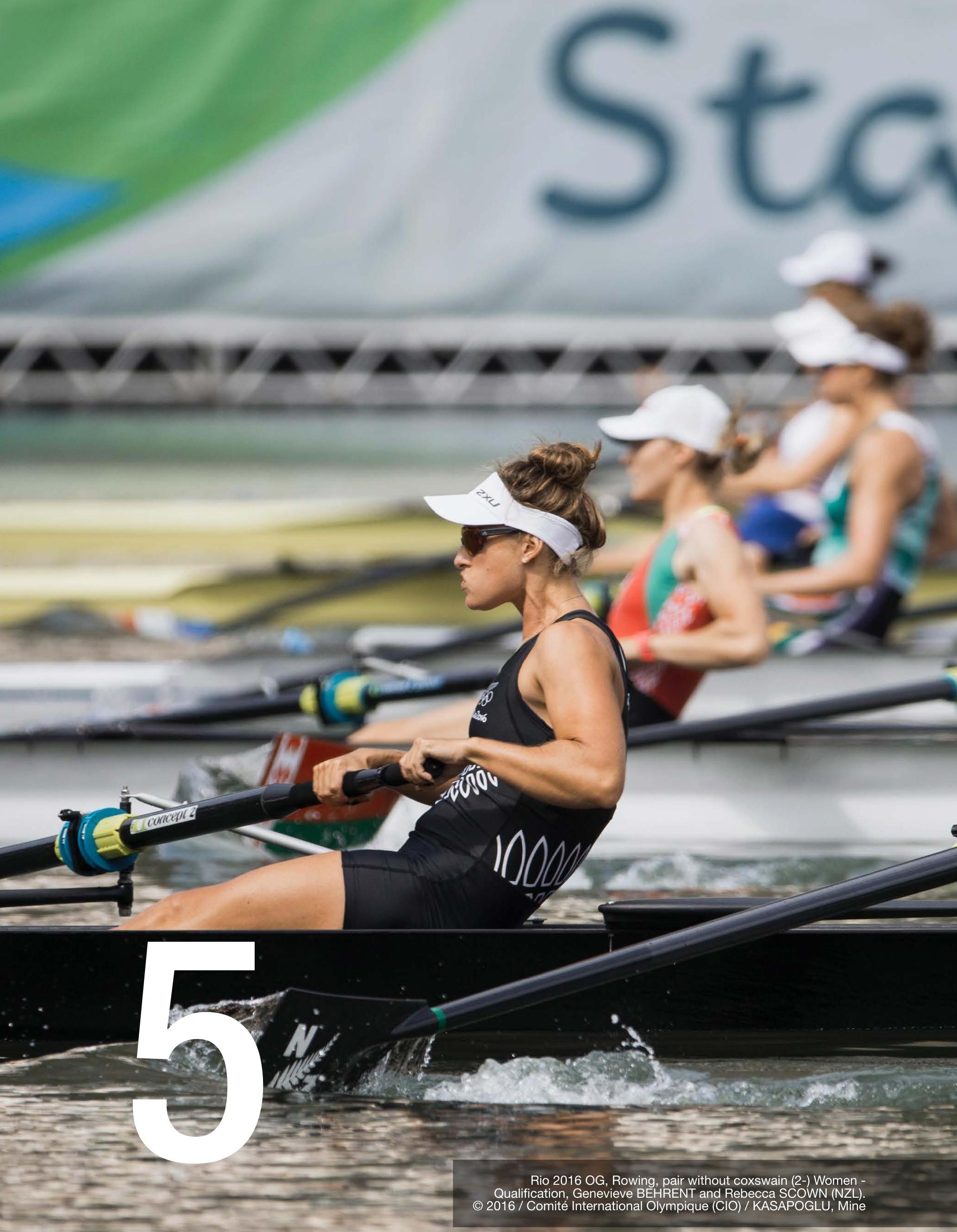




\section{Glossary and resources}

\subsection{Glossary}

Biological diversity: The variability among living organisms from all sources including, inter alia, terrestrial, marine, and other aquatic ecosystems and the ecological complexes of which they are part; this includes diversity within species, between species, and of ecosystems. (Convention on Biological Diversity, 1992)

Biodiversity loss: Biodiversity loss is usually observed as one or all of: (1) reduced area occupied by populations, species, and community types, (2) loss of populations and the genetic diversity they contribute to the whole species, and (3) reduced abundance (of populations and species) or condition (of communities and ecosystems). The likelihood of any biodiversity component persisting (the persistence probability) in the long term declines with lower abundance and genetic diversity and reduced habitat area. (Glossary (2012), BBOP)

Biodiversity offsets: Biodiversity offsets are measurable conservation outcomes resulting from actions designed to compensate for significant residual adverse biodiversity impacts arising from project development after appropriate mitigation measures have been taken. The goal of biodiversity offsets is to achieve no net loss and preferably a net gain of biodiversity on the ground, with respect to species composition, habitat structure, and ecosystem function, and people's use and cultural values associated with biodiversity. (Glossary (2012), BBOP)

Cumulative impact: The total impact arising from the project (under the control of the developer); other activities (that may be under the control of others, including other developers, local communities, government); and other background pressures and trends which may be unregulated. The project's impact is therefore one part of the total cumulative impact on the environment. The analysis of a project's incremental impacts combined with the effects of other projects can often give a more accurate understanding of the likely results of the project's presence than just considering its impacts in isolation. (Glossary (2012), BBOP)
Direct impacts: An outcome directly attributable to a defined action or project activity (often also called primary impact). (Glossary (2012), BBOP)

Ecosystem: A dynamic complex of plant, animal, and micro-organism communities and their non-living environment interacting as a functional unit. (Convention on Biological Diversity, 1992)

Ecosystem approach: The ecosystem approach is a strategy for the integrated management of land, water, and living resources that promotes conservation and sustainable use in an equitable way. (Convention on Biological Diversity, 2010)

Ecosystem services: The benefits people obtain from ecosystems. These include provisioning services such as food, water, timber, and fibre; regulating services that affect climate, floods, disease, wastes, and water quality; cultural services that provide recreational, aesthetic, and spiritual benefits; and supporting services such as soil formation, photosynthesis, and nutrient cycling. (Glossary (2012), BBOP)

Habitat: The place or type of site where an organism or population naturally occurs. (Convention on Biological Diversity, 1992)

Indirect impacts: Impacts triggered in response to the presence of the project, rather than being directly caused by the project's own operations; sometimes called secondary or induced impacts. (Glossary (2012), BBOP)

Invasive Alien Species: An invasive alien species (IAS) is a species that is established outside of its natural past or present distribution, whose introduction and/or spread threaten biological diversity. (Convention on Biological Diversity, 1992)

Key Biodiversity Areas: KBAs are sites contributing significantly to the global persistence of biodiversity. (A global standard for the identification of Key Biodiversity Areas: version 1.0, IUCN, 2016) 
Mitigation hierarchy: The mitigation hierarchy is defined as:

1. Avoidance: measures taken to avoid creating impacts from the outset, such as careful spatial or temporal placement of elements of infrastructure, in order to completely avoid impacts on certain components of biodiversity.

2. Minimisation: measures taken to reduce the duration, intensity, and/or extent of impacts, including, as appropriate, direct, indirect, and cumulative impacts (including from climate change), that cannot be completely avoided, as far as is practically feasible.

3. Rehabilitation/restoration: measures taken to rehabilitate degraded ecosystems or restore cleared ecosystems following exposure to impacts that cannot be completely avoided and/ or minimised.

4. Offset: measures taken to compensate for any residual significant, adverse impacts that cannot be avoided, minimised, and/or rehabilitated or restored, in order to achieve no net loss or a net gain of biodiversity. Offsets can take the form of positive management interventions, such as restoration of degraded habitat; arrested degradation; or averted risk through protection of areas where there is imminent or projected loss of biodiversity. (Glossary (2012), BBOP)

No Net Loss/Net Gain/Net Positive Impact: A target for a development project in which the impacts on biodiversity caused by the project are balanced or outweighed by measures taken to avoid and minimise the project's impacts, to undertake on-site restoration, and finally to offset the residual impacts, so that no loss remains. Where the gain exceeds the loss, the terms 'net gain' or 'net positive impact' may be used instead of no net loss. No net loss (or net gain) of biodiversity is a policy goal in several countries, and is also the goal of voluntary biodiversity offsets. (Glossary (2012), BBOP)

Precautionary Principle: Where there are threats of serious or irreversible damage, lack of full scientific certainty shall not be used as a reason for postponing cost-effective measures to prevent environmental degradation. (Rio Declaration, 1992. Principle 15)
Protected area: A protected area is a clearly defined geographical space, recognised, dedicated, and managed, through legal or other effective means, to achieve the long-term conservation of nature with associated ecosystem services and cultural values. (IUCN Definition 2008)

Restoration: The process of assisting the recovery of an area or ecosystem that has been degraded, damaged, or destroyed. The aim of ecological restoration is to re-establish the ecosystem's composition, structure, and function, usually bringing it back to its original (pre-disturbance) state or to a healthy state close to the original. An ecosystem is restored when it contains sufficient biotic and abiotic resources to sustain itself structurally and functionally and can continue its development without further assistance or subsidy. It will demonstrate resilience to normal ranges of environmental stress and disturbance and interact with contiguous ecosystems in terms of biotic and abiotic flows and cultural interactions. Ecological restoration strives to alter the biota and physical conditions at a site, and is frequently confused with rehabilitation. While restoration aims to return an ecosystem to a former natural condition, rehabilitation implies putting the landscape to a new or altered use to serve a particular human purpose. Activities such as ecological engineering and various kinds of resource management, including wildlife, fisheries and range management, agroforestry, and forestry, may qualify as ecological restoration if they satisfy the criteria set out by the Society for Ecological Restoration, which lists nine attributes as a basis for determining when restoration has been accomplished. (Society for Ecological Restoration)

Rights-based approach: A rights-based approach is an approach to conservation that respects, and seeks to protect and promote, recognised human rights standards ( $\underline{\mathrm{IUCN}})$.

Threatened species: These are species categorized as Critically Endangered, Endangered, or Vulnerable by The IUCN Red List of Threatened Species $^{\mathrm{TM}}$. The IUCN Red List of Threatened Species ${ }^{\mathrm{TM}}$ is widely recognized as the most comprehensive, objective global approach for evaluating the conservation status of plant and animal species. (IUCN Red List of Threatened Species ${ }^{\mathrm{TM}}$ ) 


\subsection{Resources}

A Cross-Sector Guide for Implementing the Mitigation Hierarchy (2015), Cross Sector Biodiversity Initiative. http://www.csbi.org.uk/wp-content/uploads/2015/09/CSBI-Mitigation-Hierarchy-GuideSept-2015-1.pdf

BBOP Standard on Biodiversity Offsets and associated material. http://bbop.forest-trends.org/pages/ guidelines

Biodiversity for Business: A guide to using knowledge products delivered through IUCN (2014), IUCN. https://portals.iucn.org/library/sites/library/files/documents/2014-004.pdf

Costanza, R, R de Groot, P Sutton, S van der Ploeg, S J. Anderson, I Kubiszewski, S Farber, R. K Turner (2014), Changes in the global values of ecosystem services, Global Environmental Change 26 (2014) 152-158. https://doi.org/10.1016/j.gloenvcha.2014.04.002

Cultural and Spiritual Value of Biodiversity (1999), United Nations Environment Programme, http://staging. unep.org/pdf/Cultural Spiritual thebible.pdf

Hardner, J, RE Gullison, S Anstee, and M Meyer. (2015), Good Practices for Biodiversity Inclusive Impact Assessment and Management Planning, Prepared for the Multilateral Financing Institutions Biodiversity Working Group. https://publications.iadb.org/bitstream/handle/11319/7094/Good Practices for Biodiversity Inclusive Impact Assessment.pdf? sequence=1

Human Rights Indicators - A Guide to Measurement and Implementation (2012), Office of the United Nations High Commissioner for Human Rights. United Nations. http://www.ohchr.org/Documents/ Publications/Human_rights_indicators_en.pdf

IUCN Policy on Biodiversity Offsets (2016), IUCN. https://portals.iucn.org/library/sites/library/files/ resrecfiles/WCC 2016 RES 059 EN.pdf

IFC Performance Standards on Environmental and Social Sustainability (2012). International Finance Corporation. https://www.ifc.org/wps/wcm/connect/c8f524004a73daeca09afdf998895a12/IFC Performance Standards.pdf?MOD=AJPERES

Cambridge Conservation Initiative (2015). Strengthening implementation of the mitigation hierarchy: managing biodiversity risk for conservation gains. - Collaborative Fund Project Report compiled by: BirdLife International, UNEP-WCMC, RSPB, FFI and the University of Cambridge. http://www.birdlife. org/sites/default/files/attachments/cci report - managing risk for conservation gains - final june 9th 2015.pdf

Conservation International. The value of carbon forest offset (2011), . http://www.conservation.org/ publications/Documents/2011 04 14 Value of Forest Carbon Offsets.pdf 


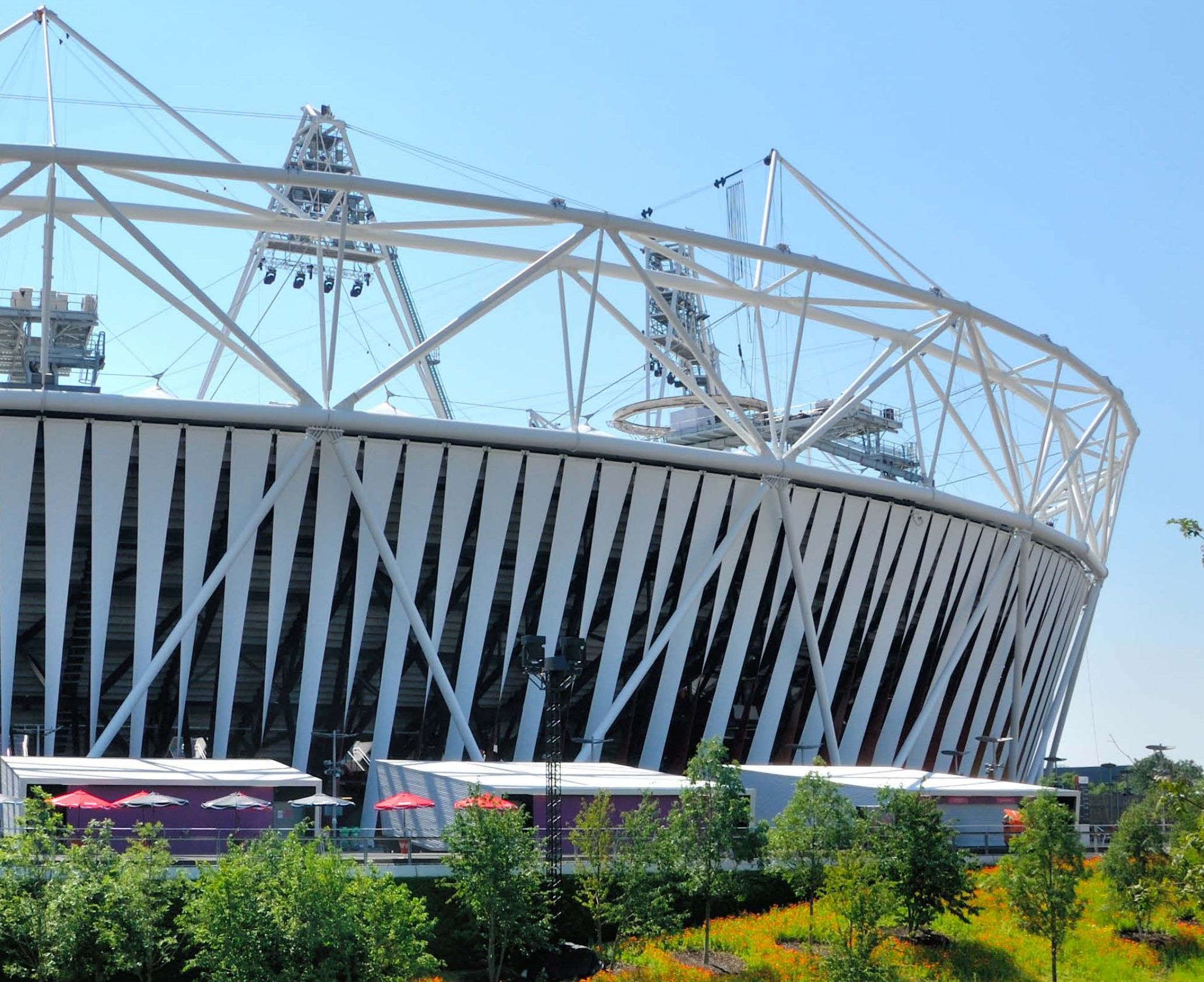

\section{(2)}

Tath $\mathrm{H}$

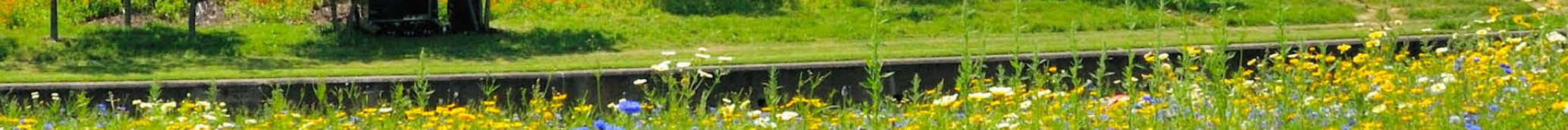

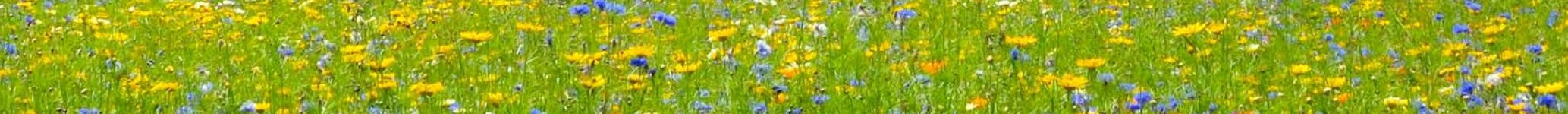

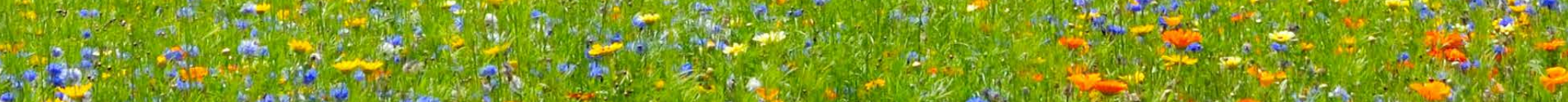
7)

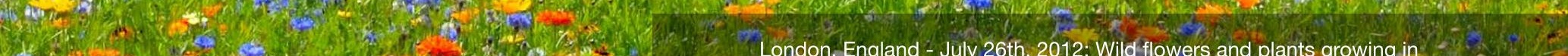

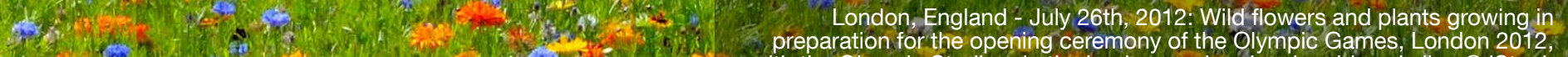

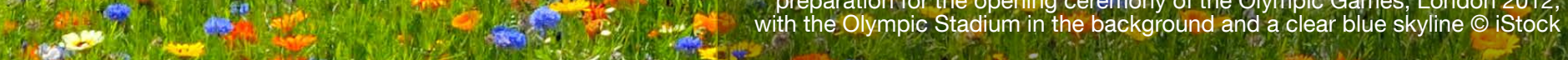

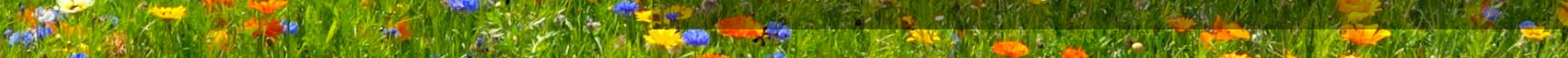

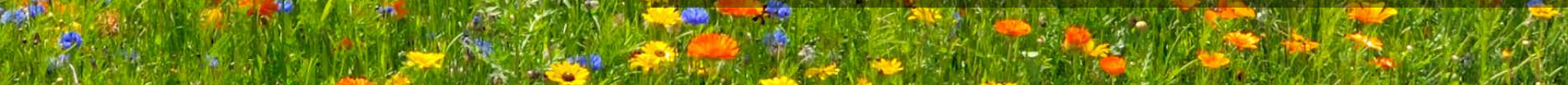

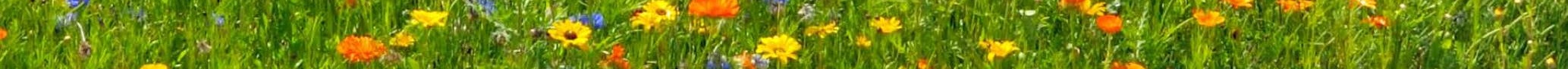






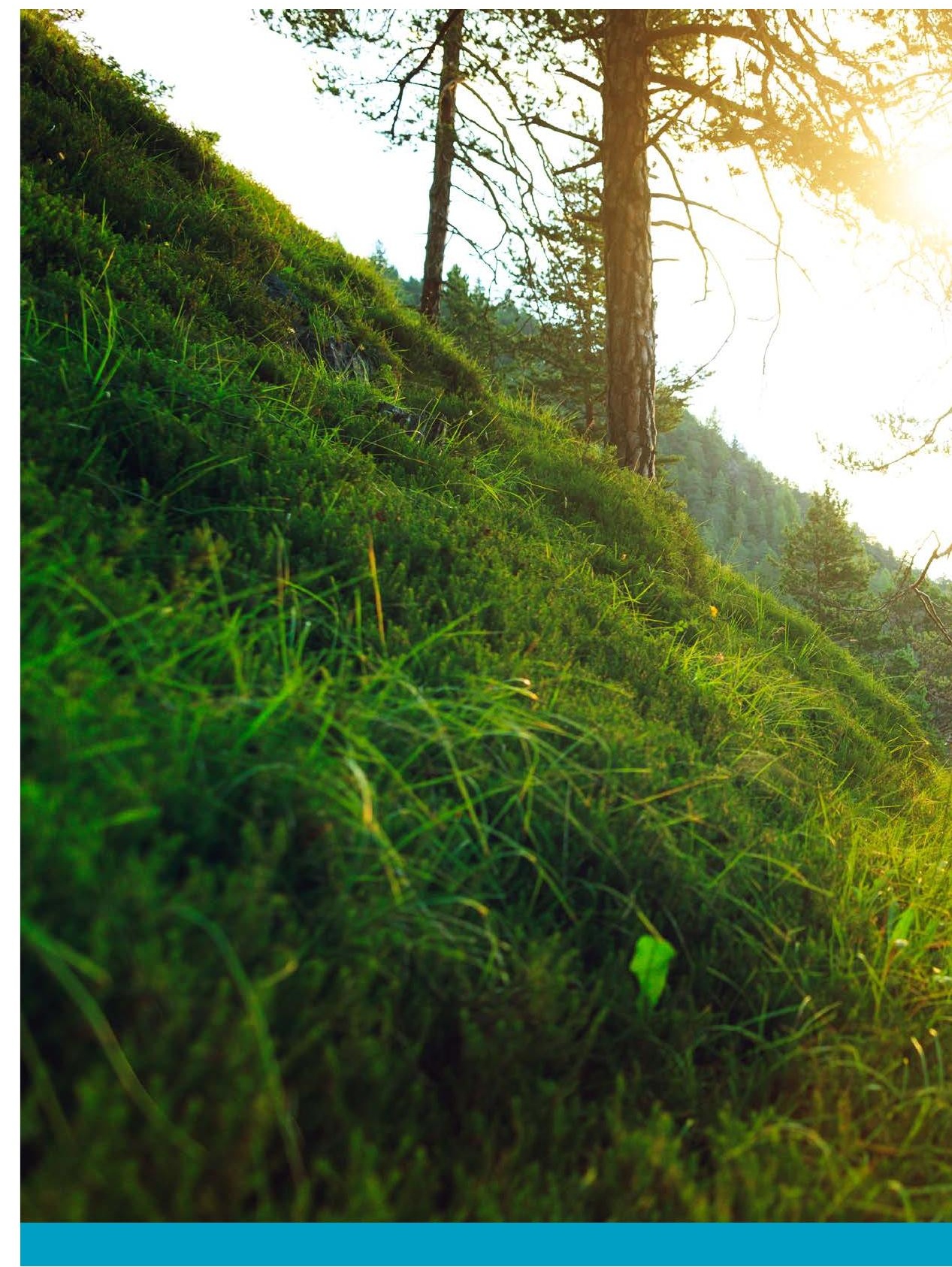

INTERNATIONAL UNION FOR CONSERVATION OF NATURE

GLOBAL BUSINESS AND BIODIVERSITY PROGRAMME

Rue Mauverney 28

1196 Gland

Switzerland

Tel +41229990000

Fax +41 229990002

www.iucn.org 